\title{
Understanding sources of sea lice for salmon farms in Chile
}

Kristoffersen, A.B., ${ }^{1,2}$ Rees, E.E., ${ }^{3}$ Stryhn, H., ${ }^{3}$ Ibarra, R., ${ }^{4}$ Campisto J-L ${ }^{4}$, Revie, C.W., ${ }^{3}$ St-Hilaire, $\mathbf{S}^{3^{*}}$.

${ }^{1}$ National Veterinary Institute, Pb 750 Sentrum, 0106 Oslo, Norway

${ }^{2}$ University of Oslo, Department of Informatics, P.O. Box 1080, Blindern, N-0316 Oslo, Norway

${ }^{3}$ Department of Health Management, Atlantic Veterinary College, University of Prince Edward Island, Charlottetown PE C1A 4P3

${ }^{4}$ Deparment of Fish Health, Instituto Tecnologico del Salmon, Av Juan Soler Manfredini 41 OF 1802, Puerto Montt, Chile

*Corresponding author tel: 902-620-5190, fax: 902-620-5053, ssthilaire@ upei.ca 


\begin{abstract}
The decline of fisheries over recent decades and a growing human population has coincided with an increase in aquaculture production. As farmed fish densities increase, so have their rates of infectious diseases, as predicted by the theory of density-dependent disease transmission. One of the pathogens that has emerged with the growth of salmon farming is sea lice. Effective management of this pathogen requires an understanding of the spatial scale of transmission. We used a two-part multi-scale model to account for the zero-inflated data observed in weekly sea lice abundance levels on rainbow trout and Atlantic salmon farms in Chile, and to assess for internal (farm) and external (regional) sources of sea lice infection. We observed that the level of juvenile sea lice was higher on farms that were closer to processing plants with fish holding facilities. Further, evidence for sea lice exposure from the surrounding area was supported by a strong positive correlation between the level of juvenile sea lice on a farm and the number of gravid females on neighboring farms within $30 \mathrm{~km}$. The relationship between external sources of sea lice from neighboring farms and juvenile sea lice on a farm was one of the strongest detected in our multivariable model. Our findings suggest that the management of sea lice should be coordinated between farms and should include all farms and processing plants with holding facilities within a relatively large geographic area. Understanding the contribution of pathogens on a farm from different sources is an important step in developing effective control strategies.
\end{abstract}

Key words: Sea lice, density-dependent pathogen, area management, salmon aquaculture, twopart random effects model 


\section{Introduction}

As salmon farming around the world responds to an expanding market the number of farms and the number of fish on farms increases. An indirect effect of this growth has been an increase in the potential for the spread of density-dependent infectious pathogens. Density-dependent transmission is observed in many pathogen-host systems (Anderson and May, 1991, Grenfell \& Dobson, 1995), including sea lice on salmon farms.

In Chile, the predominant sea lice species infecting farmed fish is Caligus rogercresseyi, and since 2008 there has been a bi-weekly government-mandated monitoring program to assist in the management of this ectoparasite (Bravo, 2003; Hamilton-West et al. 2012) ${ }^{1}$. This program is used for early detection of sea lice infections on farms and for implementation and monitoring of control strategies. The extent and frequency of the data collected as part of an industry-wide monitoring program provides a unique opportunity to assess pathogen movement within a vast aquatic system where there are large sentinel populations of animals.

The control and prevention of sea lice on salmon farms requires targeting adult female sea lice which are the source of copepodids, the parasite's infective stage. Juvenile lice on fish originate from either existing adult sea lice on fish within the same farm or from adult lice on fish outside the farm (i.e. external sources). Salmon farmers in Chile and elsewhere have been treating fish on their farms to reduce the number of adult sea lice and the risk of re-infection. Despite efforts to prevent re-infection of sea lice within farms, many industries around the world struggle to control this parasite, suggesting that treatments are not working effectively and/or external sources of lice play an important role in maintaining elevated lice levels on farms. Identifying

\footnotetext{
${ }^{1}$ As of May 2012 all farmers are required report sea lice abundance weekly.
} 
and controlling external sources of infection has been a challenge for farmers partially because the two to three week time delay between egg production and the infective stage is sufficient time for larvae to disperse long distances from their hatching site (Boxaspen 2006; Amundrud \& Murray 2009; Foreman et al. 2009).

The role of neighboring farms as a source of infective copepodids for farms has become more of a concern as aquaculture industries grow in size. Several recent studies have detected a strong association between the sea lice levels on farms and the abundance of fish hosts in the surrounding area (Krkosek et al. 2011; Jansen et al. 2012). Anecdotal evidence of this phenomenon in Chile occurred between 2007 and 2009 when there was a large reduction in sea lice levels on farms from a mean abundance of 10 adults per fish in 2007 to 1.8 in 2009 (SalmonChile), which coincided with the large decrease in biomass on farms and in farming areas at the same time. It also appears that sea lice numbers have begun to rise again in the last two years as the industry has increased in size (with a mean of 3.0 adults per fish in 2011; SalmonChile). This trend has not been objectively assessment controlling for confounders, such as changes in treatment strategies over time, but it is consistent with the host density-dependent nature of sea lice.

Another management practice that has not been assessed and may be hampering area-wide sea lice control efforts is the movement of infected fish to holding facilities for harvesting. Some processing plants have fish holding facilities to which fish are transported and held for up to 5 days prior to harvest. These holding facilities provide the processing plants with flexibility for scheduling transport and harvest of fish, but they may also increase the risk of pathogen introduction into an area. Although a number of researchers have evaluated risk factors for sea 
lice, none have examined the role of these holding facilities (Zagmutt-Veraga et al. 2005; Yatabe et al. 2011).

Another factor which has not been evaluated under field conditions is the effect of having shellfish facilities in close proximity to salmon farms. Researchers in North America have shown that bivalves can filter the free swimming life stages of Leptheophthrius salmonis (Davenport et al. 2000; Lehane and Davenport, 2006; Molloy et al. 2011). The idea of using an integrated multi-trophic aquaculture system, which includes culturing bivalves and salmon in close proximity, has been proposed as a means of reducing nitrogenous waste and sea lice on finfish farms (MacDonald et al. 2011; Molloy et al. 2011). Chile's salmon industry, which has over 800 finfish leases and grows over 221,000 tons of Atlantic salmon, 203,000 tons of rainbow trout, and 154,000 tons of coho salmon annually, shares the coastline with 1200 shellfish leases that produce approximately 280,000 tons of shellfish per year. The natural co-existence of these two large industries provides an opportunity to evaluate the relationship between bivalves and $C$. rogercresseyi on fish farms under field conditions. The goal of this study was to better understand the factors affecting the sea lice infection pressure on salmon farms in Chile to improve mitigation efforts.

\section{Methods}

\section{Study area and data}

We assessed 443 Atlantic salmon and rainbow trout marine farms in Chile's most intense aquaculture regions (between $41^{\circ} \mathrm{S}$ and $47^{\circ} \mathrm{S}$; Figure 1). Our study did not include farms from the extreme south (south of $47^{\circ} \mathrm{S}$ ) or those producing coho and chinook because these farms had no 
sea lice, or had low counts with very little variation. The mean temperature and salinity for our study area were $11.2^{\circ} \mathrm{C}$ and 29 (parts per thousand [ppt]), respectively (Table 1).

All data for his study were obtained through the Chilean salmon farmers association (SalmonChile http://www.salmonchile.cl) electronic sea lice monitoring program. Farmers reported on a weekly (occasionally biweekly) basis the mean number of sea lice per fish (abundance) based on a sample of approximately 40 fish collected from four cages. Sea lice were identified by several life-stage categories, but for the purpose of this study we only examined counts for juvenile lice and gravid females. "Juveniles" were defined as all chalimus stages of $C$. rogercresseyi. Gravid females were adult lice with attached egg strings. Average abundances for these two stages of lice were calculated based on their total counts divided by the number of fish examined at a given sample point. The abundance of juvenile sea lice was used as our outcome variable in the statistical analysis because it represents the earliest stage of infection. We used farm data collected between January 2009 and April 2012.

SalmonChile also provided point coordinate locations for all Atlantic salmon and rainbow trout farms and fish processing plants with fish holding facilities. The coordinates of shellfish leases were provided by the government of Chile (Servicio Nacional de Pesca y Acuicultura ), the governing body for aquaculture in Chile, though no information was available as to the exact periods over which these leases had been active.

\section{Description of the variables used in the statistical analysis}

Although we were primarily interested in source of sea lice for fish farms we included a number of factors that could potentially be associated, indirectly or directly to the abundance of juvenile sea lice on a fish farm in our model to correct for potential confounding. Factors were divided 
into three categories for organizational purposes: 1) potential sources of sea lice for the farm; 2) environmental factors affecting survival of sea lice; and 3) farm management factors potentially affecting the abundance of sea lice on fish.

\section{Potential sources of sea lice:}

We estimated the exposure to infective copepodids originating from within the farm from the mean abundance of reported gravid sea lice on the farm two weeks prior $\left(G F_{t-2}\right)$. The two-week lag time approximated the time required for eggs to develop into the copepodid stage at the mean sea water temperature in Chile (Gonzalez and Carvajal 2003; Bravo 2010).

To assess the external sources of sea lice infection on farms, we included variables representing sea lice infection from fish holding facilities at processing plants and from neighboring farms. We determined seaway distances between all farms, and between farms and holding facilities at processing plants using the gdistance package in $\mathrm{R}$ (www.r-project.org). The direction and force of the water currents could not be incorporated in this measurement because the data were not available; however, our estimate of seaway distances corrected for land masses between sites.

The infection pressure on farm $i$ at time $t$ from neighboring farms ( $\operatorname{LGF}_{i, t}$ ) was determined by summing the potential output of lice from neighbors weighted by their distance to the farm. The potential output of sea lice at farm $j$ was computed by multiplying the abundance of gravid sea lice two weeks prior on each of the neighboring farms $\left(G F_{j, t-2}\right)$ by the number of fish $\left(N_{j, t-2}\right)$. The weights $\left(w\left(d_{i, j}\right)\right)$ were obtained from the seaway distance $\left(d_{i, j}\right)$ and a Gaussian kernel density with a band width equal to approximately one fourth of the total width, similar to what was used by Jansen et al. (2012). The resulting formula was: 
$L G F_{i, t}=\sum_{j \in A_{i}} \mathrm{GF}_{\mathrm{j}, \mathrm{t}-2} w\left(d_{i, j}\right) N_{j, t-2}$

Where $\mathrm{A}_{i}$ was the area included within the Kernel's range.

To assess the distance where the effect of neighboring farms no longer contributed significantly to juvenile sea lice on farms we evaluated the output of lice from the neighbors at varying maximum distances (i.e. kernel ranges) of 5, 10, 20, 30 and $40 \mathrm{~km}$. Missing values for gravid sea lice counts or number of fish on a site were imputed by taking the average of values reported at $t-1$ and $t-3$ whenever these were present. This resulted in a total of 1460 imputed values for $G F_{j, t-2}$ and $N_{j, t-2}$.

The sea lice exposure from fish holding facilities could not be quantified because these facilities were not included in the monitoring program. Hence, we assessed the exposure from these sites by including the farm's seaway distance to the nearest holding facility. Similarly we included the seaway distance to the nearest shellfish farm among the predictors of interest.

\section{Environmental factors:}

Salinity (ppt) and temperature $\left({ }^{\circ} \mathrm{C}\right)$ were estimated at the farm level using a 3-week rolling average at times $t-1, t-2$, and $t$. Some farms did not report values for temperature and salinity. To fill in these missing data (77 temperature and 1952 salinity values) we imputing values from farms within a weighted seaway distance of $40 \mathrm{~km}$ using a kernel function for the same week. 
There are two distinct geographic regions in our study area that are separated by a large flow of water (Figure 1). Farms were categorized into either of these regions based on their latitude; north $\left(\leq 43.5^{\circ} \mathrm{S}\right.$ latitude) or south $\left(>43.5^{\circ} \mathrm{S}\right.$ latitude).

Farm management factors and fish characteristics:

Factors pertaining to the management practices on a farm included number of fish on a farm, the mean weight of the fish at week $t$, a proxy for the age of the fish , the species of fish, sea lice treatment, and the number of juvenile sea lice the week prior ( $\mathrm{t}-1)$. We included the latter to control for the the carry-over effect of lice on a farm from one week to the next as the weekly abundance of juvenile lice modeled was intended to represent "new" infections(Gonzalez and Carvajal, 2003).

The predominant form of sea lice treatment in Chile during our study period was bath treatment using pyrethroids, which could potentially affect juvenile sea lice on fish. Therefore we considered whether there was a sea lice treatment on a farm two weeks prior ( $\mathrm{t}-2)$ in our study. A two week lag period for sea lice treatment was used because it can take more than a week to complete a bath treatment on a farm and the effect on juveniles is sometimes delayed a few days. Further, given the life cycle of sea lice, new infections from adults within the farm should not reoccur within two weeks if the treatment was successful.

\section{Statistical model}

We used a multivariable two-part random effects model (Tooze et al. 2002; Liu et al. 2008) to determine factors affecting the mean abundance of juvenile sea lice at farm $i$ for week $t\left(\mathrm{Y}_{i, t}\right)$. This model permitted us to account for a substantial proportion of zeros (i.e., $Y_{i, t}=0$ ) in the dataset (12.4\%). We modeled the odds of the mean juvenile abundance being greater than zero 
(part I) using a logistic regression model, and the mean juvenile sea lice abundance (part II) given that counts were greater than zero using a gamma regression model. Both parts of the model included farm random effects to account for repeated measures within the farms. Potential autocorrelation between weekly measures of juvenile sea lice was accounted for by including a time-lagged outcome $\left(\mathrm{Y}_{t-1}\right)$ among the predictors.

In summary the model equations were:

$\operatorname{logit}\left(\pi_{i, t}\right)=X_{i, t}^{I} \beta^{I}+\mu_{1, i} \quad$ and $\quad \ln \left(u_{i t}\right)=X_{i, t}^{I I} \beta^{I I}+\mu_{2, i}$

Where $\pi_{i, t}=\mathrm{P}\left(Y_{i, t}>0\right)$, is the probability of a non-zero abundance, and $\mu_{i t}=\mathrm{E}\left(\mathrm{Y}_{i, t} \mid Y_{i, t}>0\right)$ is the mean zero abundance, modeled by a gamma distribution with a constant shape parameter. The pairs of random effects for farms were modeled as $\left[u_{1}, u_{2}\right] \sim \mathrm{N}\left([0,0],\left[\sigma_{1}^{2}, \rho \sigma_{1} \sigma_{2}, \sigma_{2}^{2}\right]\right)$. The model was implemented in SAS PROC NLMIXED (SAS® 9.1.3 for Windows, SAS Institute Inc., Cary, NC) and estimated by adaptive Gaussian quadrature, as previously described (Tooze et al. 2002; Liu et al. 2010).

\section{Model building:}

We explored several models to determine the most appropriate combinations of predictors, as well as forms of the predictors (i.e. binary or continuous on either original or log scale) to include in our model. Predictors were included in or excluded from the analysis simultaneously in both parts of the model. Two time lagged sea lice count variables (juvenile sea lice and gravid sea lice) were included as binary predictors in Part I and as log scale continuous predictors in Part II of the model. We added 0.1 to the predictors prior to the log transformation so that we did not lose data with the value zero. Salinity was assessed both on original scale and on restricted 
scales with lower cutoffs at 15, 20 or 25 ppt and an upper cutoff of $30 \mathrm{ppt}$, based on known biological effects of salinity on sea lice (Bricknell et al. 2006; Bravo et al. 2008). Distance to a shellfish lease was dichotomized at seaway distances of $0.5,1$ and $2 \mathrm{~km}$ from the farm to determine the best model fit. Similarly, distance to nearest holding facility was also explored in binary versions at cut-off distances of 5, 10, and $20 \mathrm{~km}$.

Model selection used Akaike's Information Criterion (AIC). Models with a difference in AIC, $\Delta \mathrm{AIC} \leq 4$, from the top ranked model provided effectively equal support (Burnham and Anderson, 2004).

As a diagnostic tool, the observed number of farms with no sea lice (abundance $=0$ ) was compared to the expected number of zero values across the dataset, as predicted by part I of the model. For part II of the model, the Anscombe residuals (McCullagh and Nelder, 1989) were inspected visually by plotting them against all explanatory variables and the fitted values. For farms with continuous observations for more than 15 weeks, the autocorrelation of the Anscombe residuals within each farm was calculated. We also assess unexplained seasonal variation by fitting a sinusoidal function with a period of 52 weeks in both parts of the model.

The top ranked model was re-fitted after standardizing the quantitative predictors to enable a direct comparison of the magnitudes of effects. For regression coefficient we computed the odds ratio (Part I) or mean ratio (Part II) to aid in their quantitative interpretation, by exponentiating the unstandardized coefficients. For predictors on the natural log scale, the coefficient was multiplied by $\ln (2)=0.693$ prior to exponentiation in order to achieve a ratio corresponding a doubling in the variable. 


\section{Results}

There were 19,714 farm weekly sea lice reports in our dataset between January 2009 and April 2012 from Atlantic salmon and rainbow trout farms. When the mean abundance of juvenile sea lice on farms was summarized by individual predictor variables there were several dose response trends that emerged (Table 1). Juvenile sea lice apparently increased with increasing 1) numbers of gravid females on farms two weeks preceding, 2) numbers of gravid females two weeks prior in the surrounding area within $30 \mathrm{~km}$ of a farm, 3)salinity, and 4) weight of the fish (Table 1). There was a decreasing trend in the abundance of juvenile sea lice as the distance to a holding facility increased. These patterns were also present in the AIC top ranked multivariable model (Tables 2 and 3).

\section{Multivariable model}

Sources of sea lice:

We found the abundance of juvenile sea lice on farms was sensitive to the spatial scales of the predictor variables representing external infection pressures. Neighboring farms, on average, impacted sea lice abundance up to a distance of $30 \mathrm{~km}$ (Table 4). For every doubling in the exposure pressure from neighboring farms there was, on average a 1.12 time increase in the mean (non-zero) abundance of sea lice , after controlling for the other predictors in the model (Table 2). Likewise, the logistic regression component of our model suggested that when the exposure on neighboring farms increased the probability of having lice on a farm also increased (Table 2). The standardized coefficient for the infection pressure of sea lice from within a farm was smaller than that of the infection pressure from the surrounding farms (Table 2); however both variables were influential in the model (Tables 2 and 3). In our logistic regression model, 
where we evaluated the presence or absence of gravid females as a dichotomous variable, farms with gravid females two week prior, had on average, approximately 5.5 times the odds of having juvenile sea lice, after controlling for the other predictors in the model (Table 2). However, the increase in the abundance of juvenile sea lice was only by a factor of 1.03 for each doubling in abundance of gravid sea lice at $\mathrm{t}-2$. In comparison, there was a 1.12 time increase in the juvenile sea lice abundance for each doubling in the exposure pressure from neighboring farms (Table 2).

The other variable that represented external sea lice infection pressure on farms, proximity to holding facilities, was also maintained in our final model. The farther the distance to the nearest holding facility the less likely a farm was to have juvenile sea lice $(\mathrm{OR}=0.68)$ (Table 2$)$. When the distance to the nearest holding facility was halved the odds of having any juvenile sea lice was $1.5(1 / 0.68)$ times higher and, on average there was a 1.05 (i.e. 1/ 0.95) increase in the abundance of juvenile sea lice (Table 2). The log scale of this parameter, compared to other forms evaluated, produced the model with the lowest AIC (Table 4).

Juvenile sea lice appeared to decrease as the distance to the nearest shellfish lease increased when no other variables were considered (Table 1). However, after accounting for other predictors the distance to the nearest shellfish lease did not contribute to the abundance in juvenile sea lice ( $\triangle \mathrm{AIC} \leq 4$; Tables 3 and 4$)$.

\section{Environmental factors:}

All three environmental parameters tested in our analysis were retained in our final model based on our AIC criterion (Table 3). However, the standardized coefficient estimate for temperature was relatively small, particularly in Part II of our model (Table 2). The effect of salinity, among 
our different threshold models, was best described using a lower threshold effect of 20 ppt and an upper threshold of $30 \mathrm{ppt}$ (Table 4). Region, which accounted for broad-scale area effects, was still significantly associated with the abundance of juvenile sea lice on farms (Table 2). The farms in the Southern region had, on average lower levels of lice even after accounting for other predictors in the model (Table 2).

Farm management factors and fish characteristics:

Our proxy for the duration of time at sea for fish, average fish weight, had a positive association with our outcome, abundance of juvenile sea lice (Table 2). Farms that treated for sea lice two weeks prior, had on average a higher odds of having juvenile sea lice after controlling for the other predictors in both components of our statistical model (Table 2). Including this variable in the model had no effect on the other parameter estimates (changes were only observed at the second decimal place on the standardized parameter estimates) suggesting this variable was not a confounder.

The variable in our final model that had the strongest effect on the abundance of juvenile sea lice on a farm was the abundance of juvenile sea lice on the farm the week before (Table 2). When the species of fish (Atlantic salmon vs rainbow trout) was included in the model it did not decrease the AIC so it was dropped from our final model

\section{Model fit:}

The observed number of weekly reports with no sea lice was similar to the sum of the predicted number of zero values (2444 observed vs 2427 predicted). This suggested the logit component of our model (part I) fit the data well. No discernible patterns were observed from plotting the residuals from part II of the model against all explanatory variables and the fitted values, 
suggesting that the gamma regression model also fit the data well. Further, evaluation of the residuals from the subset of data containing farms that had 15 weeks of consecutive sea lice reports $(75.8 \%$ of all the data) had less than $2.9 \%$ autocorrelation. When seasonal effect was modeled using a sinusoidal function in both parts of our model the AIC value only decreased by three and the parameter estimates for the other predictors did not change. We therefore concluded that any seasonal effect was sufficiently controlled for by including the salinity, temperature, and region parameters without the need to explicitly model season.

\section{Discussion}

We used a two-part random effects model to assess potential sources of juvenile C. rogercresseyi infection on Atlantic salmon and rainbow trout farms in Chile. Both variables in our model representing external sources of sea lice were positively associated with juvenile lice on a farm. The greater the exposure potential from neighboring farms within $30 \mathrm{~km}$ the higher the abundance of juvenile sea lice. Similarly farms closer to processing plants with fish holding facilities had a higher abundance of juvenile sea lice than farms farther away from these plants, and the closer the farms were to these facilities the greater the effect, even after controlling for potential confounders such as other sources of lice.

The average effect of holding facilities on juvenile sea lice abundance appeared to be relatively lower than the average effect of the infection pressure from neighboring farms. We may have underestimated the effect of holding facilities in our study because we did not have data available to differentiate between weeks when there were fish with sea lice and when there were no fish or fish with no lice present at these facilities; however, it is likely that the infection pressure from neighboring farms is a stronger driver of juvenile sea lice than proximity to 
holding facilities because of the 10 fold increase in the number of fish at grow-out facilities, in comparison with temporary holding facilities (per. Comm. R. Ibarra, SalmonChile). Further, fish at holding facilities are usually harvested within one week. Caligus rogercresseyi can produce egg strings every 4 to 6 days, depending on water temperature (Bravo 2010). Therefore, if fish are infected with mature lice when they arrive at the holding facility there is only sufficient time to release one set of egg strings before they are harvested.

Surprisingly, in our final model the standardized coefficient estimate for the infection pressure from neighboring farms was also larger than the coefficient for the abundance of gravid females within the farm, which suggests that neighboring farms are a stronger driver of with-in farm sea lice dynamics than the farm itself (Part II continuous model, Table 2). There are at least two biologically plausible explanations for this finding. First, it is possible, given that it takes between 1 and 2 weeks for eggs to reach the infective stage, that by the time copepodid originating within a farm have developed they have been flushed away from the original site via water currents. It is also possible that producers control the level of re-infection on their farms relatively well by treating adult sea lice, but despite industry efforts to synchronize treatments in neighborhoods, they do not control treatments on their neighbors farms.

Interestingly the salmon industry is reporting relatively good efficacy of sea lice treatments against adult lice (i.e. on average, in 2011, the industry reported a $70 \%$ reduction in adult sea lice 1 week post bath treatments; SalmonChile), but similar to the findings of other researchers (Revie et al. 2003; Lees et al. 2008a), we found a positive association between treatment and juvenile sea lice abundance. This suggests that the treatments, on average, are not effectively controlling juvenile sea lice on farms. This finding could be due to a number of reasons such as treatment failure due to resistance or poor product application, or use of a product that has no 
effect on the juvenile stages. It could also reflect the fact that farms that treat for sea lice are generally in areas that have high levels of lice, and the use of bath treatments, which were the most common types of sea lice treatments in our study, do not prevent new infections from external sources. A better understanding of the role of treatments on juvenile stages of sea lice is essential in order to control re-infections with the parasite.

Also consistent with external sources of sea lice having a stronger association with juvenile sea lice abundance on a farm than internal sources was the fact that the number of fish on the farm was negatively associated with the abundance of juvenile lice on that farm (Table 2). Given the host density-dependent nature of sea lice infections and the fact that we used the abundance of gravid females on a farm (not the absolute number of gravid females) as the predictor variable, if the source of juvenile lice was predominantly the fish within the farm we would have expected the opposite relationship. However, if the source of sea lice was predominantly external to the farm, sea lice abundance on the farm would be mostly independent of the farm fish population size. This being the case, as the farm fish population increased, there would be more fish exposed to a finite number of copepodids coming from external sources. As a consequence, the infection pressure could get diluted, as observed in other pathogen-host systems (Randolph \& Dobson, 2012), and this may be observed as a negative association between hosts and pathogen numbers. A similar observation has been made for C. elongatus infection on Scottish fish farms where that species, in contrast to L. salmonis, is seen to be primarily driven by external infection pressure (Revie et al. 2002b).

Based on this study, the average distance of the "neighbor effect" in Chile is greater than currently estimated by some of the neighborhood designations (Figure 1). Given our model, which controlled for environmental factors affecting sea lice, as well as farm and fish 
characteristics, it appears that, on average, farms within $30 \mathrm{~km}$ of each other should be managed for sea lice concurrently to reduce infection levels. Logistically, it is unlikely that it will be feasible to synchronize sea lice treatments over such a large area given the spatial distribution of farms; therefore, a sea lice control strategy that could be investigated in the future is the use of buffer zones to break up larger management areas. One approach to creating these buffer zones without losing production may be to use coho salmon, a farmed species that is less susceptible to sea lice infections (Fast et al. 2002; Bravo, 2003). It should be noted that this strategy may not work for controlling other density-dependent pathogens if they do not share the same susceptibility patterns.

It is important to remember that the critical average threshold distance to manage farms, determined in this study, was based on sea lice data collected between 2009 and 2012 and did not include hydrological data. Therefore if the number of fish on farms and their proximity to one another changes the infective zone around farms will also change.

Another management strategy that has been proposed for controlling sea lice is the use multitrophic aquaculture using bi-valves. We evaluated whether fish on farms close to a shellfish lease were less likely to be infected with juvenile sea lice. The basic trend between distance to a shellfish lease and juvenile sea lice on a farm was the opposite of what was expected, given laboratory and field observations in Canada with Lepeophtheirus salmonis (Davenport et al. 2000; Lehane and Davenport, 2006; Molley et al. 2011) (Table 1). When we accounted for confounding factors in the multivariable analysis we found this variable did not improve the model, based on AIC model selection techniques. This result may be because the species of sea lice in Chile is of a different size than reported in the laboratory studies, and thus may not be filtered in a similar manner as the species found in Canada. It is also possible that shellfish leases 
in close proximity to finfish farms reduce the water flow and thus inhibit the dispersion of free swimming stages from within the farms. If this was the case, any beneficial effects of filtering external sources of sea lice could be negated by the increased exposure from lice produced within the farm. We did not have information on the water currents near farms to evaluate the possible confounding effect between water flow and shellfish leases.

Of arguable importance, the assessment of proximity to shellfish leases on juvenile sea lice evaluated in this study was limited by lack of data on whether or not shellfish leases were active over the three years of data collection. Therefore, we likely underestimated the impact of shellfish leases, if there truly was an effect. It should also be noted that approximately $97 \%$ of the shellfish leases were in the Northern region, so a proportionally larger number of the control group (farms farther than the specified distance to a shellfish lease) came from the Southern region. However, we controlled for region within the model. In conclusion, our data analysis does not support the hypothesis that shellfish leases significantly reduce the level of sea lice on Chilean salmon farms; however, it should be reiterated that the data where such that it cannot be concluded with certainty that this association does not exist without further evaluation.

All other variables included in our model had previously been demonstrated to be associated with sea lice by other researchers (Revie et al. 2003; Yabata et al. 2011; Jansen et al. 2012). We refined some of the predictors in the previously published sea lice models; for example, we included salinity, but instead of using a continuous variable to describe this parameter we used a continuous variable with upper and lower threshold effects that described the biological effect on sea lice (Bravo et al. 2008). We evaluated three lower cut-offs and found that a lower limit of 20 ppt and upper limit of $30 \mathrm{ppt}$ best explained our data. 
The effect of temperature in our model was relativity modest, especially in the case of part II, which modeled expected abundance of juvenile lice. The sea water temperatures in Chile where the study sites were located were well within the optimal growth range for sea lice (90\% temperature range 8.9 to $14.5^{\circ} \mathrm{C}$ (Table 1). The lack of a strong temperature impact on population level sea lice abundance mirrors results from Scotland where similar sea water temperature profiles were experienced (Revie et al. 2003; Robbins et al. 2010). This is in contrast to finding from Norway (Jansen et al. 2012) where a broader range of water temperatures were likely the reason that this parameter was found to be important (Heuch et al. 2003).

Farms in the Southern region of our study were less likely to have sea lice and, on average, a lower abundance of juvenile sea lice than farms in the north, after controlling for the other predictors in the model (Table 2). The regional difference could have been due to risk factors that were different between the two regions, and for which we did not have data available to assess (e.g., the sea lice contributions of wild fish populations, the role of ocean hydrology on sea lice dispersion, etc.).

Our analysis was consistent with other studies with regards to the positive relationship between the weight of fish and sea lice abundance (Jansen et al. 2012). It has been proposed by other researchers that the older the fish the more time it has had to accumulate lice and the larger the surface area for attachment, thus the heavier the infection loads (Revie et al. 2002a; Lees et al. 2008b; Baillie et al. 2009; Heuch et al. 2009; Yatabe et al. 2011; Jansen et al. 2012).

Although our two part model addressed the issue of modeling a dataset with numerous zero counts and appears to fit the juvenile sea lice data in Chile, the parameter estimates are still averages for the industry, which may limit its application to individual farms. The model is also 
only valid for the range of data from which it was developed. The estimated effects of the explanatory variables mostly behaved as predicted and were consistent with previous models of adult sea lice in Chile and in other parts of the world. It is possible that our model could have been improved by further refining our explanatory variables; for example, by including information on the role of wild fish or ocean hydrology. Some of the unexplained variation in our model may also have been due to the variation in the estimates of the juvenile sea lice counts on farms. The early attached stages of sea lice are difficult to identify. However, even with this potential source of error our model fit the data relatively well, suggesting we included the most important predictors of juvenile sea lice.

\section{Conclusion}

It is likely that the aquaculture industry will continue to grow. To contend with the predicted increase in density-dependent pathogens such as sea lice it will be necessary to manage sources of infection risk. Our study demonstrates that in the case of sea lice these risks may not be confined to the farm-level. Although the spread of sea lice from neighboring farms and holding facilities has been suspected, this is the first analysis in Chile that has tested this hypothesis. Farms closer to holding facilities and to other farms have, on average, a higher abundance of juvenile sea lice than those more distant from them. Our results also suggest that waterborne transmission of sea lice may occur over a large area so maintaining low levels of gravid sea lice on farms and at holding facilities in an area should help reduce the level of juvenile sea lice. The scale over which external sources of sea lice play a role in maintaining infections, in part, depends on intensity of farming at the regional level. Determining this spatial scale is important for the successful management of sea lice. 


\section{Acknowledgements}

We would like to thank CORFO Chile for assisting with the funding of this project and William Chalmers for editing the manuscript.

\section{Conflict of interest statement}

The authors declare that they have no competing interests. 


\section{References}

Amundrud, T.L., Murray, A.G., 2009. Modelling sea lice dispersion under varying environmental forcing in a Scottish sea loch. J. Fish Dis. 32, 27-44.

Anderson, R.M., May, R.M., 1991. Infectious diseases of humans: dynamics and control. Oxford and New York: Oxford University Press.

Baillie, M., Lees, F., Gettinby, G., Revie, C.W., 2009. The use of prevalence as a measure of sea lice burden: A case study of Lepeophtheirus salmonis on Scottish Atlantic salmon (Salmo salar L) farms. J. Fish Dis. 32, 15-25.

Boxaspen, K., 2006. A review of the biology and genetics of sea lice. ICES J. Mar. Sci. 63, 1304-1316.

Bravo, S., 2003. Sea lice in Chilean salmon farms. Bull. Europ. Assoc. Fish Pathol. 23,197-200.

Bravo, S., Pozo, V., Silva, M.T., 2008. The tolerance of Caligus rogercresseyi to salinity reduced in southern Chile. Bul. Europ. Assoc.Fish Pathol. 28,198-206.

Bravo, S., 2010. The reproductive output of sea lice Caligus rogercresseyi under controlled conditions. Exp. Parasitol. 125(1), 51-54.

Bricknell, I.R., Dalesman, S.J., O’Shea, B., Pert, C.C., Mordue Luntz, A.J., 2006. Effect of salinity on sealice Lepeoptheirus salmonis settlement success. Dis, Aquat. Org. 71, 201-212.

Burnham, K.P., Anderson, D.R., 2004. Multimodel Inference: Understanding AIC and BIC in Model Selection. Sociol. Meth. Res. 33, 261-304.

Chang, B.D., Page, F.H., Beattie, M.J., Hill, B.W., 2011. Sea louse abundance on farmed salmon in the southwestern New Brunswick area of the bay of fundy. In: Jones, S. and Beamish, R. (Eds.), Salmon Lice: An Intergrated Approach to Understanding Parasite Abundance and Distribution. Wiley-Blackwell, Oxford, UK, pp. 83-115.

Davenport, J., Smith,R.J.J.W., Packer, M., 2000. Mussels Mytilus edulis: significant consumers and destroyers of mesozooplankton. Mar. Ecol. Prog. Ser. 198, 131-137.

Fast, M.D., Ross, N.W., Mustafa1, A., Sims, D.E., Johnson, S.C., Conboy, G.A., Speare, D.J., Johnson, G., Burka, J.F., 2002. Susceptibility of rainbow trout Oncorhynchus mykiss, Atlantic salmon Salmo salar and coho salmon Oncorhynchus kisutch to experimental infection with sea lice Lepeophtheirus salmonis. Dis. Aquat. Org. 52, 57-68.

Foreman, M.G.G., Czajko, P., Stucchi, D.J., Guo, M., 2009. A finite volume model simulation for the Broughton Archipelago, Canada. Ocean Model 30,29-47.

Gonzalez, L., Carvajal, J., 2003. Life cycle of Caligus rogercresseyi, (Copepoda: Caligidae) parasite of Chilean reared salmonids. Aquaculture 220, 101-117. 
Grenfell, B.T., Dobson, A. P. (ed.), 1995. Ecology of infectious diseases in natural populations. Cambridge: Cambridge University Press.

Hamilton-West, C., Arriagada, G., Yatabe, T., Valdes, P., Herve-Claude, L.P., Urcelay, S., 2012. Epidemiological description of the sea lice (Caligus rogercresseyi) situation in southern Chile in August 2007. Prev. Vet. Med. 104, 341-345.

Heuch, P.A., Revie, C.W., Gettinby, G., 2003. A comparison of epidemiological patterns of salmon lice (Lepeophtheirus salmonis) infections in Norway and Scotland. J. Fish Dis. 26,539551.

Heuch, P.A., Stigum, O., Malkenes, R., Revie, C.W., Gettinby, G., Baillie, M., Lees, F., Finstad B., 2009. Temporal and spatial variations in lice numbers on salmon farms in the Hardanger fjord 2004-2006. J. Fish Dis. 32, 89-100.

Jackson, D., Hassett, D., Copley, L., 2002. Integrated lice management on Irish salmon farms. Fish. Vet. J. 6, 28-38.

Jansen, P.A., Kristoffersen, A.B., Viljugrein, H., Jimenez, D., Aldrin, M., Stien, A., 2012. Sea lice as a density-dependent constraint to salmonid farming. Proc. R. Soc. B. 279(1737), 23302338.

Krkosek, M., Connors, B. M., Ford, H., Peacock, S., Mages, P., Ford, J.S., Morton, A., Volpe, J.P., Hilborn, R., Dill, L.M., Lewis, M. A., 2011. Fish farms, parasites, and predators: implications for salmon population dynamics. Ecol Applic., 21, 897-914.

Lees, F., Baillie, M., Gettinby, G., Revie, C.W., 2008a. Factors associated with changing efficacy of emamectin benzoate against infestations of Lepeophtheirus salmonis on Scottish salmon farms. J. Fish Dis. 31, 947-951

Lees, F., Gettinby, G., Revie, C.W., 2008b. Changes in epidemiological patterns of sea lice infestation on farmed Atlantic salmon (Salmo salar L) in Scotland between 1996 and 2006. J. Fish Dis. 31, 251-262.

Lehane,C., Davenport, J., 2006. A 15-month study of zooplankton ingestion by farmed mussels (Mytilus edulis) in Bantry Bay, Southwest Ireland. Estuar. Coast. Shelf Sci. 67, 645-652.

Liu, L., Strawderman,R.L., Cowen, M.E., Shih, Y-C.T., 2010. A flexible two-part random effects model for correlated medical costs. J. Health Econ. 29, 110-123.

Liu, L., Ma, J. Z., Johnson, B., 2008. A multi-level two-part random effects model, with application to an alcohol dependence study. Stat. Med. 27, 3528-3539.

Lovdata, 2010. FOR 2010-07-14 nr 1123: Forskrift om sone for å forebygge og bekjempe lus i akvakulturanlegg i kommunene Os, Samnanger, Fusa, Tysnes, Austevoll, Kvinnherad, Jondal, 
Kvam, Fitjar, Stord, Bømlo, Sveio, Vindafjord og Etne kommuner, Hordaland og Rogaland. http://www.lovdata.no/cgi-wift/ldles?doc=/lf/lf/lf-20100714-1123.html

MacDonald, B.A., Robinson, S.M.C., Kelly, A., Barrington, K.A., 2011. Feeding activity of mussels (Mytilus edulis) held in the field at an integrated multi-trophic aquaculture (IMTA) site (Salmo salar) and exposed to fish food in the laboratory. Aquaculture 314, 244-251.

McCullagh, P., Nelder, J. A., 1989. Generalized Linear Models, Second Edition. Chapman and Hall, London.

Molloy, S.D., Pietrak, M.R,, Bouchard, D.A., Bricknell, I., 2011. Ingestion of Lepeophtheirus salmonis by the blue mussel Mytilus edulis. Aquaculture 311, 61-64

Rae, G.H., 2002. Sea louse control in Scotland, past and present. Pest. Man. Sci. 58, 515-520. Revie, C.W., Gettinby, G., Treasurer, J.W., Grant, A.N., Reid, S.W.J., 2002a. Sea lice infestation on Atlantic salmon and the use of ectoparasitic treatments on commercial farms in Scotland. Vet. Record 28, 753-757.

Revie, C.W., Gettinby, G., Treasurer, J.W., Rae,G.H., 2002b. The epidemiology of the sea lice, Caligus elongatus Nordmann, in marine aquaculture of Atlantic salmon, Salmo salar L., in Scotland. J. Fish Dis. 25, 391-399.

Revie, C.W., Gettinby, G., Treasurer, J.W., Wallace, C., 2003. Identifying epidemiological factors affecting sea lice (Lepeophtheirus salmonis) abundance on Scottish salmon farms using general linear models. Dis. Aquat. Org. 57, 85-95.

Robbins, C., Gettinby, G., Lees, F., Baillie, M., Wallace, C., Revie, C.W., 2010. Assessing topical treatment interventions on Scottish salmon farms using a sea lice (Lepeophtheirus salmonis) population model. Aquaculture 306, 191-197.

Tooze, J.A., Grunwald, G.K., Jones, R.H., 2002. Analysis of repeated measures data with clumping at Zero. Stat. Meth. Med. Res. 11, 341-355

Yatabe, T., Arriagada, G., Hamilton-West, C., Urcelay, S., 2011. Risk factor analysis for sea lice, Caligus rogercresseyi, levels in farmed salmonids in southern Chile. J. Fish Dis. 34, 345-354.

Zagmutt-Vergara, F.J., Carpenter, T.E., Farver, T.B., Hedrick, R.P., 2005.Spatial and temporal variations in sea lice (Copepoda: Caligidae) infestations of three salmonid species farmed in net pens in southern Chile. Dis. Aquat. Org. 64, 163-173 
Table 1: Descriptive statistics of the explanatory parameters retained in the top ranked AIC model and their relationship with the outcome variable, abundance of juvenile sea lice.

\begin{tabular}{|c|c|c|c|c|c|}
\hline & $\begin{array}{c}\text { Mean value } \\
\text { for } \\
\text { parameter }\end{array}$ & $\begin{array}{l}90 \% \text { range for } \\
\text { parameter }\end{array}$ & $\begin{array}{c}\text { Parameter } \\
\text { levels }\end{array}$ & $\begin{array}{l}\text { Mean abundance of } \\
\text { juvenile sea lice for } \\
\text { different parameter } \\
\text { levels }\end{array}$ & $\begin{array}{l}90 \% \text { range of juvenile } \\
\text { sea lice abundance for } \\
\text { different parameter } \\
\text { levels }\end{array}$ \\
\hline \multirow[t]{4}{*}{ Juvenile sea lice at $t-1$} & 1.32 & $0-4.40$ & $0-0.20$ & 0.12 & $0.00-0.52$ \\
\hline & & & $0.20-0.70$ & 0.66 & $0.13-1.62$ \\
\hline & & & $0.70-1.58$ & 1.26 & $0.30-2.70$ \\
\hline & & & $>1.58$ & 3.32 & $0.53-9.14$ \\
\hline \multirow{4}{*}{$\begin{array}{l}\text { Gravid female lice on } \\
\text { farm at } t-2\end{array}$} & 1.17 & $0-3.82$ & $0-0.1$ & 0.39 & $0.00-1.97$ \\
\hline & & & $0.10-0.73$ & 1.10 & $0.06-3.48$ \\
\hline & & & $0.73-1.52$ & 1.43 & $0.18-3.58$ \\
\hline & & & $>1.52$ & 2.43 & $0.23-7.53$ \\
\hline \multirow{3}{*}{$\begin{array}{l}\text { Gravid female lice in } \\
\text { surrounding } 30 \mathrm{~km} \\
\text { area } X 10^{5} \text { at t-2 }\end{array}$} & 0.96 & $0-2.94$ & $0-0.20$ & 0.45 & $0.00-2.05$ \\
\hline & & & $0.20-0.64$ & 1.15 & $0.00-3.58$ \\
\hline & & & $0.64-1.34$ & 1.52 & $0.10-4.43$ \\
\hline Salinity (ppt) & 29 & $18-33$ & $\begin{array}{c}>1.34 \\
<20 \\
20-30 \\
>30\end{array}$ & $\begin{array}{l}2.23 \\
0.13 \\
0.87 \\
1.53\end{array}$ & $\begin{array}{l}0.20-7.08 \\
0.00-0.81 \\
0.00-3.13 \\
0.10-4.10\end{array}$ \\
\hline Temperature $\left({ }^{\circ} \mathrm{C}\right)$ & 11.2 & $8.9-14.5$ & $\begin{array}{c}<10 \\
10-13 \\
>13\end{array}$ & $\begin{array}{l}1.23 \\
1.46 \\
1.05\end{array}$ & $\begin{array}{l}0.00-3.63 \\
0.00-4.88 \\
0.00-4.00\end{array}$ \\
\hline
\end{tabular}




\begin{tabular}{|c|c|c|c|c|c|}
\hline \multirow{4}{*}{$\begin{array}{l}\text { Distance }(\mathrm{km}) \text { to } \\
\text { nearest holding } \\
\text { facility }\end{array}$} & \multirow[t]{4}{*}{98.7} & \multirow[t]{4}{*}{$10.1-198.4$} & $<5$ & 2.42 & $0.17-11.70$ \\
\hline & & & $5-10$ & 2.45 & $0.00-6.64$ \\
\hline & & & $10-20$ & 2.24 & $0.05-8.08$ \\
\hline & & & $>20$ & 1.17 & $0.00-3.87$ \\
\hline \multirow{4}{*}{$\begin{array}{c}\text { Distance }(\mathbf{k m}) \text { to } \\
\text { nearest shellfish lease }\end{array}$} & \multirow[t]{4}{*}{70.0} & \multirow[t]{4}{*}{$0.28-238.2$} & $<0.5$ & 1.94 & $0.00-7.18$ \\
\hline & & & $0.5-1$ & 1.53 & $0.00-4.97$ \\
\hline & & & $1-2$ & 1.23 & $0.00-4.85$ \\
\hline & & & $>2$ & 1.23 & $0.00-3.93$ \\
\hline \multirow[t]{3}{*}{ Average weight (kg) } & \multirow[t]{3}{*}{1.91} & \multirow[t]{3}{*}{$0.27-4.79$} & $<0.5$ & 0.85 & $0.00-3.05$ \\
\hline & & & $0.5-1$ & 1.02 & $0.00-3.33$ \\
\hline & & & $>1$ & 1.55 & $0.00-5.05$ \\
\hline \multirow[t]{2}{*}{ Region } & & & South & 1.26 & $0.00-4.10$ \\
\hline & & & North & 1.43 & $0.00-4.90$ \\
\hline \multirow[t]{2}{*}{ Species } & & & Rainbow trout & 1.29 & $0.00-4.43$ \\
\hline & & & Atlantic salmon & 1.38 & $0.00-4.45$ \\
\hline \multirow[t]{2}{*}{ Treatment at $t-2$} & & & No & 1.18 & $0.00-3.95$ \\
\hline & & & Yes & 2.31 & $0.15-7.58$ \\
\hline \multirow{4}{*}{$\begin{array}{l}\text { Number of fish on } \\
\quad \text { farm }\left({\left.\mathrm{x} 10^{6}\right)}^{-}\right.\end{array}$} & \multirow[t]{4}{*}{0.76} & \multirow[t]{4}{*}{$0.19-1.21$} & $<0.60$ & 1.63 & $0.00-5.55$ \\
\hline & & & $0.60-0.78$ & 1.37 & $0.00-4.26$ \\
\hline & & & $0.78-0.96$ & 1.35 & $0.00-4.73$ \\
\hline & & & $>0.96$ & 1.01 & $0.00-3.45$ \\
\hline
\end{tabular}


Table 2. Parameter coefficient estimates, standard errors, $p$-values, and odds/mean ratios for the explanatory variables in the AIC top ranked model for abundance of juvenile sea lice on Atlantic salmon and rainbow trout farms in Chile. Part I of the model indicates the probability of the abundance of juvenile sea lice being greater than zero, and part II models the expected abundance of juvenile sea lice given that a farm has this stage of sea lice. All reference for dichotomous variables was "no" unless otherwise stated.

\begin{tabular}{cccccc}
\hline & & & & Standardized & Odds ratio \\
Coefficient & Standard & & coefficient & or Mean \\
Variable name & estimate & Error & $p$-value & estimate & ratio* $^{*}$ \\
\hline
\end{tabular}

\section{Part I Logit model}

$$
\text { intercept }
$$

Juveniles t-1

Gravid females t-2

$\log _{10}$ of \# of gravid females weighted by distance within

$30 \mathrm{~km}$

Salinity

$\log _{10}$ of distance to nearest

holding facility

$\log _{10}$ of weight

Region (North as reference)

Temperature

Number of fish on farm

Treatment $\mathrm{t}-2$
$-0.069$

1.001

2.907

0.111

1.704

0.115

$<0.001$

$<0.001$

2.917

1.704

18.29

5.49

0.798

0.076

$<0.001$

0.820

1.74

0.160

0.020

$<0.001$

0.546

1.17

$-0.547$

0.138

$<0.001$

$-0.454$

0.68

0.125

0.071

0.079

0.103

1.09

$-1.088$

0.248

$<0.001$

$-0.950$

0.34

$-0.104$

0.026

$<0.001$

$-0.170$

0.90

0.382

0.164

0.020

0.127

1.47

0.489

0.250

0.050

0.483 


\section{Part II continuous model}

intercept

$\log _{10}$ of number of juvenile

sea lice $\mathrm{t}-1$

$\log _{10}$ of number of gravid

females $\mathrm{t}-2$

0.006

$<0.001$

0.053

1.03

$\log _{10}$ of \# of gravid females

weighted by distance within

$30 \mathrm{~km}$

0.160

0.008

$<0.001$

0.168

1.12

Salinity

0.028

0.004

$<0.001$

0.092

1.03

$\log _{10}$ of distance to nearest

holding facility

$-0.076$

0.025

0.002

$-0.070$

0.95

$\log _{10}$ of weight

0.094

0.008

$<0.001$

0.075

1.07

Region (north as reference)

$-0.203$

0.050

$<0.001$

$-0.193$

0.82

Temperature

$-0.007$

0.004

0.064

$-0.012$

0.99

Number of fish

$-0.110$

0.024

$<0.001$

$-0.034$

0.90

Treatment t-2

0.189

0.015

$<0.001$

0.189

1.21

$\log _{10}$ of shape parameter

0.877

0.010

0.877

Farm stand deviation (Part I)

0.300

0.016

1.142

Farm stand deviation (Part II)

1.163

0.120

0.299

Farm correlation

0.394

0.084

* ratios are for a one unit change or for a doubling when the predictor was on a log scale 
Table 3. Difference in the AIC, $\triangle \mathrm{AIC}$, between the top ranked model in Table 2 (AIC $=32355$, with a $\mathrm{K}=26$ ) and a model excluding indicated explanatory variable. The higher the $\triangle \mathrm{AIC}$ values the higher the AIC for the revised model. $\mathrm{K}$ is the number of parameters in the nested model (note: we removed variables from both components of the model simultaneously).

\begin{tabular}{lll}
\hline Description of the change made to the top ranked model (AIC= 32355) & $\Delta$ AIC & K \\
\hline Excluded juvenile sea lice one week prior & 8101 & 24 \\
Excluded gravid females & 260 & 24 \\
Excluded sea lice exposure pressure from neighboring farms & 474 & 24 \\
Excluded treatment two weeks prior & 155 & 24 \\
Excluded mean fish weight (kg) & 135 & 24 \\
Excluded salinity & 101 & 24 \\
Excluded number of fish on farm & 24 & 24 \\
Excluded region & 24 & 24 \\
Excluded log of the distance to the nearest holding facility & 16 & 24 \\
Excluded log of the temperature & 14 & 24 \\
Included species & 2 & 28 \\
Included whether there was a shellfish lease within 2 km of the site & 1 & 28 \\
\hline
\end{tabular}


Table 4. Difference in the AIC, $\triangle \mathrm{AIC}$, between the top ranked model in Table $2(\mathrm{AIC}=32355)$ and various forms of different variables. The top ranked model had 26 variables. All model changes were undertaken in both parts of the model simultaneously.

\begin{tabular}{|c|c|c|c|}
\hline variable & $\begin{array}{l}\text { Description of the change made to the variable } \\
\text { in the top ranked model }(\mathrm{AIC}=32355)^{*}\end{array}$ & AIC & $\Delta \mathrm{AIC}$ \\
\hline \multirow{6}{*}{$\begin{array}{l}\text { Kernel weighted } \\
\text { intensity of gravid } \\
\text { female lice at t-2 for } \\
\text { different distances } \\
\text { from the farm (LGF) }\end{array}$} & Top ranked model includes $\log (\mathrm{LGF})$ at $30 \mathrm{Km}$ & 32255 & $\mathbf{0}$ \\
\hline & Replacing with $\log _{10}(L G F)$ at $20 \mathrm{~km}$ & 32370 & 15 \\
\hline & Replacing with $\log _{10}(L G F)$ at $40 \mathrm{~km}$ & 32371 & 16 \\
\hline & Replacing with $\log _{10}(L G F)$ at $10 \mathrm{~km}$ & 32548 & 193 \\
\hline & Replacing with $\log _{10}(L G F)$ at $5 \mathrm{~km}$ & 32684 & 329 \\
\hline & Model excluding all forms of this variable & 32829 & 474 \\
\hline \multirow[t]{4}{*}{ Salinity } & Top ranked model includes Salinity ${ }_{20,30}(t)$ & 32355 & $\mathbf{0}$ \\
\hline & Replaced with Salinity $15,30(\mathrm{t})$ & 32368 & 13 \\
\hline & Replaced with $\mathrm{Sal}_{25,30}(\mathrm{t})$ & 32375 & 20 \\
\hline & Model excluding all forms of this variable & 32456 & 101 \\
\hline \multirow[t]{5}{*}{$\begin{array}{l}\text { Seaway distance to } \\
\text { nearest holding facility }\end{array}$} & $\begin{array}{l}\text { Top model includes } \log _{10}(\text { distance to holding } \\
\text { facility) }\end{array}$ & 32355 & $\mathbf{0}$ \\
\hline & Replaced with binary form (within $20 \mathrm{~km}$ ) & 32356 & 1 \\
\hline & Replaced with binary form (within $5 \mathrm{~km}$ ) & 32364 & 9 \\
\hline & Replaced with binary form (within $10 \mathrm{~km}$ ) & 32367 & 12 \\
\hline & Model excluding all forms of this variable & 32339 & 16 \\
\hline \multirow{4}{*}{$\begin{array}{l}\text { Seaway distance to } \\
\text { nearest shellfish lease }\end{array}$} & Top rank model excludes this variable & 32355 & $\mathbf{0}$ \\
\hline & Included presence of shellfish lease within $0.5 \mathrm{~km}$ & 32359 & 4 \\
\hline & Included presence of shellfish lease within $1 \mathrm{~km}$ & 32357 & 2 \\
\hline & Included presence of shellfish lease within $2 \mathrm{~km}$ & 32356 & 1 \\
\hline
\end{tabular}

*The form of the variable in the top ranked model is presented in bold for comparison purposes. 


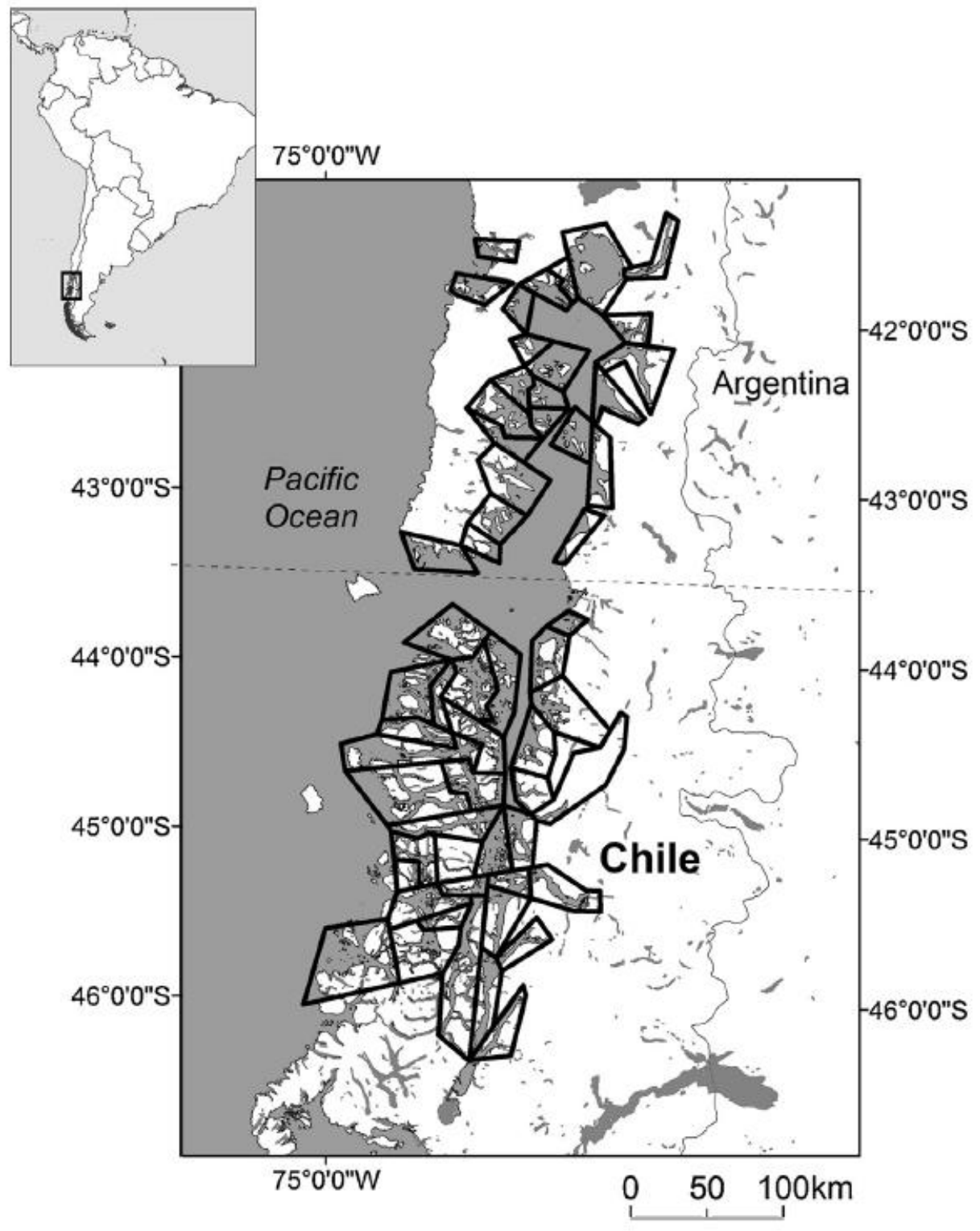

Figure 1. General location of farms included in our study and farm neighborhood areas (outlined in black) in Chile. The dashed line indicates $43.5^{\circ} \mathrm{S}$ to show the spatial divide for grouping farms north and south of this latitude for our analyses. 